\title{
Interaction Equivalency in Self-Paced Online Learning Environments: An Exploration of Learner Preferences
}

\author{
Jason F. Rhode \\ Northern Illinois University \\ USA
}

\begin{abstract}
This mixed methods study explored the dynamics of interaction within a self-paced online learning environment. It used rich media and a mix of traditional and emerging asynchronous computer-mediated communication tools to determine what forms of interaction learners in a selfpaced online course value most and what impact they perceive interaction to have on their overall learning experience. This study demonstrated that depending on the specific circumstance, not all forms of interaction may be either equally valued by learners or effective. Participants differentiated among the various learning interactions available and indicated that informal interactions were as important as formal interactions in determining the quality of the online learning experience. Participants also reported the activity of blogging as being equally valued and in some ways superior to instructor-directed asynchronous discussion via the discussion board in a learning management system.
\end{abstract}

Keywords: interaction; equivalency; mixed methods; distance education; instructional design; self-paced; online learning; online; learning environments; blogs; blogging; educational social software; social networking

\section{Introduction}

It is widely accepted that learning takes place through active engagement rather than passive transmission (S. W. Brown \& King, 2000; Dobrovolny, 2006; Jonassen, 1999; Mezirow, 1997). This principle of active intercourse with either concepts or agents has been commonly labeled as "interaction." It is through such interactions that knowledge can be constructed in a meaningful and memorable fashion. The precept of interaction is perhaps one of the most documented and disputed aspects of education, serving as a foundational component for many seminal and contemporary approaches to understanding the phenomenon of learning (Anderson, 2003). Having been hailed as one of the catalysts for movement from teacher-directed to learner- 
centered approaches, interaction is understood to be a fundamental element for quality learning environments (Flottemesch, 2000; Garrison \& Anderson, 2003; Juwah, 2006; Kearsley, 1995; Picciano, 2002; Sherry, 1996). Often conceptualized as the mechanism whereby participants in the learning environment communicate with each other and respond to each other's needs, interaction can also be generalized to reflect a wide array of processes - whether intrapersonal, interpersonal, or interfacing with technology agents (Hirumi, 2006; Mayes, 2006). In the simplest context, however, interaction is engagement in learning (Wanstreet, 2006). Yet the design and support of learning interactions that are both genuinely engaging and conceptually stimulating within online learning contexts remains a significant challenge in contemporary education as institutions seek to not only meet the needs of learners but also to accommodate the disciplinary differences in the ways that learners prefer to interact and the affordances of the communication tools selected (Ravenscroft \& McAlister, 2006; Smith, Torres-Ayala, \& Heindel, 2008).

No matter how one defines interaction, based on recent research it is clear that when the level of interaction is inadequate or nonexistent, learners often feel isolated and an overall degradation of the learning experience can take place (Bibeau, 2001; Howland \& Moore, 2002; Mann, 2005; Wanstreet, 2006). Conversely, the learning experience is enriched as learners engage in interactions within the learning environment that serve to scaffold the synthesis, evaluation, and application of knowledge (Rovai \& Barnum, 2003; Wiley, 2006). Interaction has been identified as a central component of such engaging learning environments and a catalyst for the development of thriving learning communities (Hodge, Bossé, Foulconer, \& Fewell, 2006; Swan, 2002). The higher education establishment has recognized the value of interaction as new distance education programs emerge that embrace a socially constructed paradigm and foster various levels and types of interaction (M. Brown \& Long, 2006). Often, the goal of such efforts is for learners to develop a sense of engagement by interacting in meaningful ways with each other, the instructor, and the content of the course (M. J. W. Lee \& McLoughlin, 2007; Ouzts, 2006; Rovai, 2002).

The advancement of communications technology continues to spawn new applications and opportunities for interpersonal interaction within online education, which forces designers and instructors to revisit the construct of interaction and select activities purposefully that will foster the most beneficial learning experience. The rise of synchronous and asynchronous computermediated communication (i.e., e-mail, threaded discussion, synchronous chat) combined with the integration of a structured learning management system environment has been mistakenly hailed by some as the panacea for developing quality online learning (Koszalka \& Ganesan, 2004). Reminiscent of the Clark (1994) versus Kozma (1994) debate, the battle of media versus instruction rages as educators and designers make decisions about the appropriate implementation of various media and communication technologies within the development of online learning environments. The needs and preferences of learners ought to influence such decisions.

In an effort to meet the ever-increasing needs of adult learners, educational institutions are recognizing the potential of emerging educational models that place increasing emphasis upon both formal and informal learning networks; as well, they are seeking to develop more flexible learner-paced models that provide learners the freedom to customize aspects of the learning 
experience to meet their personal and educational preferences (Dron, 2007; Kahn, 2007; Twigg, 2003). The pedagogical possibilities inherent in these emerging approaches hold great promise for adapting learning environments to meet the individual needs and preferences of learners while strengthening learning conditions that preserve learner independence (McLoughlin \& Lee, 2008b). These new models are especially attractive to administration because of the potential to not only meet the needs of the rapidly growing demographic of adult learners but also to support economies of scale (Anderson, Annand, \& Wark, 2005; Ellis, Jarkey, Mahony, Peat, \& Sheely, 2007; Taylor, 2001). Such flexible learning environments represent a unique and still unexplored segment of the expansive territory of online learning. Whereas an imposed-pace model sets definitive parameters for the course and stipulates that all learners engage in the same learning activities at specific time periods, the self-paced approach affords more autonomy to learners, allowing each to proceed at an individualized pace while providing benchmarks for progress and achievement. In contrast to an imposed-pace course that lends itself to regular or occasional collaborative activities, a self-paced course presents a challenging environment for fostering collaboration because individual learners may be at different stages of the course at any given time (Anderson et al., 2005). Rather than judge the self-paced approach as a failure to provide guidance, it is helpful to acknowledge how the self-paced approach affords learners an increased measure of flexibility in terms of the pace of engagement in the various course activities and in communications with others.

Emerging tools and approaches for interaction based upon the new social computing capabilities of the semantic Web now make possible an array of interactions not only within the specified course environment but also across learner-defined domains beyond the virtual "walls" of the course (Dalsgaard, 2006; Dron, 2006; McLoughlin \& Lee, 2008a). Learners have the opportunity to engage not only with the instructor and fellow learners in the given course but also with countless "experts" and other supporting resources that are available online only a few clicks away. As the options for interaction within the online learning environment grow, so does the necessity for identifying the types of interactions that are valued most by learners.

Substantial attention has been paid in the literature to focusing upon interaction within cohortbased, instructor-paced online environments characterized by specified start and end dates, limited entry points, and instructor-led discourse (Ho, 2005; Jung, Choi, Lim, \& Leem, 2002; J. Lee, Carter-Wells, Glaeser, Ivers, \& Street, 2006; Maor, 2003; Ouzts, 2006). Yet, the perspectives of students about their interactions within learner-paced education models is notably absent from the literature (Anderson et al., 2005). Online learning initiatives that incorporate open and self-paced approaches create unique learning environments that differ significantly in format and structure from instructor-led modes (Ngwenya, Annand, \& Wang, 2004).

\section{Interaction Equivalency Theorem}

Recognizing the wide range of learner needs and distance education program formats afforded by emerging computer-mediated communication tools as well as the reality that no single medium supports the educational experience in a manner superior to all others (Russell, 2005), Terry Anderson (2003) sought to formulate a theoretical framework for explaining the dynamics of 
learner interactions in the context of self-paced courses delivered online. He noted the utility for institutions involved in distance and online education to routinely examine and adjust delivery models to accommodate both the largest number of students and significant niche groups of learners. In an effort to account for the numerous approaches to designing online learning curriculum and to build upon previously espoused theoretical rationale regarding interaction, Anderson proposed his Interaction Equivalency Theorem:

Deep and meaningful formal learning is supported as long as one of the three forms of interaction (student-teacher; student-student; studentcontent) is at a high level. The other two may be offered at minimal levels, or even eliminated, without degrading the educational experience. High levels of more than one of these three modes will likely provide a more satisfying educational experience, though these experiences may not be as cost or time effective as less interactive learning sequences. (Anderson, 2003)

This theorem forms the foundation for an extensible model of community-based learning support, which permits learner-learner interaction in a cost effective manner while also maintaining the qualities of self-paced learning (Anderson et al., 2005). In addition to preserving the value of diverse types and quantities of interaction, Anderson's theorem opens the door for exploration of emergent curriculum designs and interaction approaches that extend beyond the common instructor-paced class model of education. This theorem implies that one type of interaction may be substituted for others without a degradation of the educational experience. Yet, this proposition of substitutivity isn't as straightforward as Anderson's theorem may suggest. Not all students may interact meaningfully with peers or content and may therefore require or prefer interaction with an instructor. Moreover, some students may prefer to interact with the content or other students in a greater proportion than with the instructor. The key to Anderson's thesis is that each student is different and requires a specific mix of interaction to fit specific preferences and needs. Numerous corollaries and implications for the design and facilitation of learning stem from the extent to which such varying interaction is perceived as being equivalent by learners.

\section{Statement of the Problem}

Interaction has long been identified as a key element to successful online learning programs (Beldarrain, 2006; Moore, 1993). While not the sole indicator of high-quality and effective online education programs, there is significant evidence to suggest that meaningful interaction with other students and the instructor is integral to the development of thriving learning environments (R. E. Brown, 2001; Garrison \& Cleveland-Innes, 2005; Greene, 2005; J. Lee et al., 2006; Swan, 2002). Such engaging interactions contribute to the development of a sense of social connectedness and have been found to enhance both the learning experience and course completion rates (Garrison, 2003; Su, Bonk, Magjuka, Liu, \& Lee, 2005; Swan \& Shih, 2005).

The rapidly expanding approaches to online education have given rise to varying theoretical bases for judging the appropriateness of incorporating interaction. Insufficient or ineffective interaction 
may lead to student isolation, whereas exorbitant levels may lead to overload or frustration (Berge, 1999; Willging \& Johnson, 2004). This study aimed to explore the preferences of learners about the various interactions they engage in during a self-paced online course while questioning the presumption espoused by Anderson (2003) that a measure of equivalency exists among these commonly identified forms of interaction in an online learning environment. Anderson's theoretical basis for judging the essential quantities of each of the various types of interaction maintains that as long as one of three primary forms of interaction (student-teacher; studentstudent; student-content) is at a high level, other forms may be minimized or eliminated without adversely affecting the learning experience. This hypothesis is increasingly attractive to institutions pursuing initiatives to rapidly expand online course offerings as it addresses the limitation that such institutions commonly face regarding the ratio of faculty to students and the amount of student-teacher interaction. This rationale is being extrapolated to support the design of learning approaches that maximize the student-content and student-student interaction and reduce the level of student-instructor interaction. Yet, little empirical evidence currently exists as to the value that learners place upon the various types of interactions in a self-paced learning environment.

\section{Method}

This exploratory study sought to examine the experiences and preferences of adult learners concerning the various interactions that they encounter in a self-paced online course. The following four primary research questions guided data collection and analysis efforts:

1. What forms of interaction do adult learners engage in most in self-paced online courses?

2. What forms of interaction do adult learners value most in self-paced online courses?

3. What forms of interaction do adult learners identify as equivalent in self-paced online courses?

4. What impact do adult learners perceive interaction to have on their self-paced online learning experience?

Building upon previous research in human-human interaction in online learning environments, this mixed methods study, which utilized a concurrent data collection methodology, documented the experiences of adult learners who participated in a self-paced online course that employed various levels of interpersonal interaction. The selection of the mixed methods framework for this research study was based upon the value of the resulting first-hand accounts from participants of their experiences and perceptions of interaction within a unique online learning environment. The resulting data from the mix of quantitative and qualitative interview questions included a combination of rich narrative accounts along with numeric frequencies of engagement. 


\section{Participants}

The participants for this study were online adult learners enrolled in a fully-online professional development certificate program offered by a private, higher education institution located in the northeastern part of the United States. This study was specifically limited to investigating the interaction experiences and preferences of self-paced online learners in order to provide in-depth data about the distinctive aspects of interaction within this unique learning ethos. The one-year online certificate program employs a self-paced, emergent, and flexible design and was selected as an appropriate context in which to explore the dynamics of the interaction preferences of adult online learners.

\section{Sample Course Characteristics}

The study sample included all learners successfully completing either of two concurrent sections of an undergraduate certificate program course in educational technology. This course utilized a unique self-paced format whereby a new cohort of learners began the course with an instructor each month. Participants were afforded the freedom to proceed through the course materials and activities at an individualized pace with the only stipulated deadline being an end-of-course deadline. The researcher happened to also serve as the course instructor and therefore was privy to the intimate details of the course design, development, and facilitation processes. Explicitly detailed research design and methods were therefore essential to combat the existent opportunity for bias as well as threats to reliability and validity.

The course was constructed within the Blackboard learning management system (LMS) and incorporated a variety of asynchronous computer-mediated communication tools standard in the LMS. The course also included integration of a personal learning landscape powered by the open source Elgg platform, which contained an assortment of social networking features such as blogging, tagging of resources, e-portfolios, and learner-driven communities. While communications within the framework of a given course only last for the duration of the course, learners can use such a learning landscape to collaborate and build networks that will be accessible long after the course(s) have ended.

The course was also a unique selection for this study in that it mandated as required learning activities the use of both the Blackboard LMS and the personal learning landscape by each of the learners. This made possible a unique discovery of learner preferences for different types of interactions fostered by these varying suites of online communication tools. Such emergent collaborations included blogging, podcasting, social bookmarking, and informal search for additional supplementary resources. In addition, the course sections selected were equally unique, as one section had only a single learner compared to fourteen learners in the other. One might expect that such a disparity of course sizes would adversely affect results as a course scenario with a lone learner would eliminate all possible interpersonal interactions beyond one-on-one contact with the course instructor. However, due to the integration of a course community and course blog that included learners in multiple sections of the same course, the lone learner in the course section had the opportunity to interact with others outside of the formal learning space in 
Blackboard. Therefore, unique comparisons and contrasts were gleaned between the perspective of the learner in a course section where formal interaction with other learners was limited and the perspectives of learners in a simultaneous course section where formal interactions with other learners were feasible.

\section{Participant Selection}

The study sample included all learners enrolled in two concurrent sections of the selected course. A common approach within education research, the convenience sampling technique, is often utilized when the characteristics of a specific group of individuals matches the attributes of the phenomenon being studied (McMillan \& Schumacher, 2006). The sample size was restricted to this select group of learners as they were the most current cohort of learners to be actively enrolled in a self-paced online course at the institution at the time of the study and had the freshest memory of their experience, which is considered vital by researchers who claim that the farther removed a participant is from the direct experience, the more problematic recall becomes (Fink \& Kosecoff, 1998). The course enrollment for the August 2007 and September 2007 sections of the course totaled fifteen learners, with one learner enrolled in the August 2007 section and fourteen learners enrolled in the September 2007 section. Invitations to participate were sent via e-mail to the eleven learners who successfully completed $75 \%$ or more of the course, of which 10 responded and agreed to participate in the study. The lone learner from the August section was among those who successfully completed the course and agreed to participate. Therefore, the resulting study sample size study was $10(n=10)$.

\section{Data Collection}

Data was collected in the form of semi-structured, in-depth interviews, which were conducted near the conclusion of the course to record the learners' perceived value of various modes of interaction as well as their interaction experiences and preferences. Transcripts of the interviews with learners were analyzed and coded for emerging themes. Self-reported frequencies of engagement in the various interactive components of the course were collected from participants during the interviews and analyzed as well. The findings include both the collective and comprehensive perspectives of the adult learners as they shared their experiences and preferences for interaction within the self-paced online education environment.

Interview questions addressed the three main types of interaction described in the literature (e.g., student-student interaction, student-instructor interaction, and student-content interaction) in regards to both formal and informal learning activities; the interview questions also explored the tenets of Anderson's (2003) Interaction Equivalency Theorem. The interviews yielded rich narrative descriptions of learners' interaction experiences, preferences, and frequencies in an attempt to understand the interaction dynamics and optimal integration within an online selfpaced adult learning program.

Since sampled learners were distributed across North America, interviews were conducted over the phone rather than in person. Interviews were comprised of semi-structured, open-ended 
interview questions about learner perceptions and preferences for interaction in the self-paced online learning environment. The interviews were conducted to gain deeper insight into learners' experiences when they engaged in the various forms of interaction within the course. All interviews were recorded digitally and then manually transcribed and coded as part of the data analysis process. The QuickTap telephone handset tap, in conjunction with a laptop computer and the audio recording software Audio Hijack Pro, was used to record each phone interview. Interviews were then manually transcribed using the software package HyperTRANSCRIBE and then coded for emerging themes. Member checking strategies were utilized and involved sending transcripts of interviews to the corresponding interviewees to confirm accuracy prior to coding.

Each interview consisted of a total of ninety-four pre-determined questions. Interview questions were derived from a review of premier themes within interaction literature and addressed the three main types of interaction described in the literature (e.g., student-student interaction, student-instructor interaction, and student-content interaction) in regards to both formal and informal learning activities. The questions also explored the tenets of Anderson's (2003) Interaction Equivalency Theorem. Questions were provided to all participants prior to the interview to allow learners to reflect on the questions and give substantive responses. At times throughout the interview, additional follow-up questions were asked to help clarify or expand upon responses.

\section{Discussion of Research Questions and Findings}

Interview questions explored the recent experiences of participants as they completed the course, noting their preferences for various interactive components of the self-paced learning experience. Questions sought both quantitative and qualitative descriptors from participants and emerging themes are summarized below.

The primary focus of this research was to investigate the preferences of learners about the various interactions they engage in during a self-paced online course while questioning the presumption espoused by Anderson (2003) that a measure of equivalency exists among these commonly identified forms of interaction in an online learning environment. A total of ten learners from among two sections of a self-paced online course participated in semi-structured, in-depth interviews and shared their first-hand experiences. Interview transcripts were reviewed and coded to determine emergent themes. The triangulation of data through multiple sources, which included verbatim transcripts, comparisons of qualitative responses to quantitative data gleaned from interview questions, reviewer notes, and member checks of transcribed interviews, aided in strengthening and validating the findings. Four primary research questions guided the research study, and each is discussed below.

Research Question 1: What forms of interaction do adult learners engage in most in self-paced online courses?

To gain a sense of the forms of interaction that learners engaged in most in a self-paced online course, participants were asked to first reflect on their overall self-paced learning experience. 
Successive questions investigated their preferences for various components of the course as well as the frequency in which they utilized such features.

Participants expressed overwhelming pleasure with the various course activities and instructional content. Such instructional content included a mix of both instructor-developed online multimedia presentations including audio and static slides as well as supplementary video presentations linked to from outside of the online course room. Others identified overarching characteristics of the course as being what they found to be the best parts of their learning experience, such as the self-paced format of the course and the opportunity to learn to use the various Web 2.0 technologies covered in the course.

Participants self-reported that they engaged most frequently in interactions involving either the course content or course instructor, on both formal and informal levels. Such interactions support the notion of the informal influence of the network and collective proposed by Anderson and Dron (2007). Emerging influences extend beyond the confines of the defined learning space and can potentially serve as an option for learners and designers alike to leverage within the selfpaced learning environment.

Participants further noted that they engaged most actively with the instructor and course content, commensurate with findings of previous research pointing to the necessity of such fundamental interactions (Gallien \& Early, 2008; Heinemann, 2003; Pawan, Paulus, Yalcin, \& Chang, 2003; Perry \& Edwards, 2005; Stein, Wanstreet, Calvin, Overtoom, \& Wheaton, 2005). The results of this study further strengthen the literature calling for the development of specific competencies not only for those designing online learning but also for those who facilitate online learning experiences of various formats (Klein, Spector, Grabowski, \& Teja, 2004; Varvel, 2007). Therefore, the interactions with the instructor as well as with the content should not be discounted.

Research Question 2: What forms of interaction do adult learners value most in self-paced online courses?

Participants were asked to rate on a scale of 1-5, with 5 being most important and 1 being least important, 30 different elements of the course. These elements varied from specific technological tools employed to pedagogical components of the course experience. Tables 1-3 depict how the respondents ranked each of the course elements. Rankings were computed by multiplying the number of responses at each rating level by the corresponding rating numerical value and then totaling. Relative frequencies and rankings are displayed in three sections of importance: highest, intermediate, and lowest. Table 1 displays the course elements ranked by participants as having highest importance. 
Table 1

Course Elements of Highest Importance

Response Frequencies

Page $\mid 10$

\begin{tabular}{|c|c|c|c|c|c|c|}
\hline & \multicolumn{2}{|c|}{ Most Importan } & \multicolumn{3}{|c|}{ Least Important } & \multirow[b]{2}{*}{ Rank } \\
\hline Course Element & 5 & 4 & 3 & 2 & 1 & \\
\hline Application Assignments & 10 & 0 & 0 & 0 & 0 & 1 \\
\hline Communications from Instructor & 8 & 2 & 0 & 0 & 0 & 2 \\
\hline Instructional Presentations & 8 & 2 & 0 & 0 & 0 & 2 \\
\hline External Resources & 8 & 2 & 0 & 0 & 0 & 2 \\
\hline Comments from Instructor to Blog Postings & 8 & 1 & 1 & 0 & 0 & 5 \\
\hline Receiving E-mail from Instructor & 8 & 1 & 1 & 0 & 0 & 5 \\
\hline Supplementary Instructional Media & 7 & 2 & 1 & 0 & 0 & 7 \\
\hline Sending E-mail to Instructor & 7 & 2 & 1 & 0 & 0 & 7 \\
\hline Course Blog & 4 & 4 & 2 & 0 & 0 & 9 \\
\hline Instructor's Bookmarks & 5 & 3 & 1 & 1 & 0 & 9 \\
\hline
\end{tabular}

The top ten elements ranked highest by participants all involved interactions either with the content or instructor. Table 2 presents course elements ranked by participants as being of intermediate importance. Again, the course content and instructor interaction items were ranked among the highest elements. 
Table 2

Course Elements of Intermediate Importance

Response Frequencies

Page $\mid 11$

Most Important Least Important

\begin{tabular}{|c|c|c|c|c|c|c|}
\hline Course Element & 5 & 4 & 3 & 2 & 1 & Rank \\
\hline Learning Landscape & 4 & 2 & 4 & 0 & 0 & 11 \\
\hline Instructor Comments to Discussion Board & 3 & 5 & 1 & 0 & 1 & 12 \\
\hline Course Bookmarks & 5 & 3 & 0 & 1 & 0 & 12 \\
\hline Learners' Bookmarks & 4 & 4 & 0 & 1 & 0 & 14 \\
\hline Personal Blog & 3 & 4 & 1 & 2 & 0 & 14 \\
\hline Course Podcast & 5 & 1 & 3 & 1 & 0 & 16 \\
\hline Learners' Blogs & 2 & 4 & 3 & 0 & 0 & 17 \\
\hline Reflection Activities & 0 & 6 & 2 & 2 & 0 & 18 \\
\hline Course Textbook & 5 & 1 & 4 & 0 & 0 & 19 \\
\hline Receiving E-mail from Learners & 0 & 6 & 2 & 2 & 0 & 20 \\
\hline
\end{tabular}

Table 3 contains the course elements ranked by participants as being of least importance. While participants ranked the majority of course elements as being at least moderately important, they consistently ranked elements involving interactions with other learners as lowest in comparison to all the possible choices. The narrative responses by participants to the remaining interview questions served to validate this trend, as participants indicate their preferences for quality content and instructor interactions and the necessity for such components in preferred self-paced online learning experiences. 
Table 3

Course Elements of Lowest Importance

Response Frequencies

Most Important Least Important

\begin{tabular}{|c|c|c|c|c|c|c|}
\hline Course Element & 5 & 4 & 3 & 2 & 1 & Rank \\
\hline Communications from Learners in Course & 0 & 4 & 5 & 0 & 1 & 20 \\
\hline Discussion Board & 0 & 3 & 6 & 0 & 1 & 22 \\
\hline Synchronous Chat with Instructor & 3 & 1 & 3 & 1 & 0 & 23 \\
\hline Sending E-mail to Learners & 1 & 2 & 4 & 1 & 2 & 24 \\
\hline Posting Comments to Discussion Board & 1 & 2 & 3 & 2 & 1 & 25 \\
\hline Posting Comments to Learners' Blog Posts & 1 & 2 & 3 & 1 & 2 & 26 \\
\hline Comments from Learners to Blog Postings & 1 & 2 & 4 & 1 & 2 & 27 \\
\hline Learner Comments to Discussion Board & 0 & 4 & 2 & 1 & 1 & 27 \\
\hline Communications from Learners Diff. Sects. & 0 & 3 & 2 & 1 & 3 & 29 \\
\hline Synchronous Chat with Learners & 0 & 1 & 5 & 1 & 1 & 30 \\
\hline
\end{tabular}

Participants rated interactions with the instructor and quality course content as the most important aspects of a self-paced course. In their ratings, learner-learner interaction trailed behind. This limited exploratory study provides only a glimpse into self-paced learning, but these findings directly support previous research that emphasizes the importance of the roles of the instructor and content in the overall quality of online learning experiences (Abdulla, 2006; Gallien \& Early, 2008; Heinemann, 2003; Perry \& Edwards, 2005; Strachota, 2003; Su, 2006; Yang \& Cornelious, 2005). Simultaneously, these findings contradict the notion purported by some that collaboration with fellow learners is either preeminent or can potentially compensate for well-designed content and active instructor involvement (Anderson et al., 2005; Rovai \& Barnum, 2003; Russo \& Benson, 2005; Tu \& McIsaac, 2002). Participants noted that although they enjoyed the interactions with other learners and often wished for more, they conceded that in the self-paced, online learning environment such interactions are challenging. The qualitative rankings applied to the course elements correspond with the qualitative responses that participants shared about the importance of various course elements. 
Participants hailed the blogging and social bookmarking activities as integral to the quality of the overall learning experience, noting the synergy of formal and informal interactions that such activities fostered. Responses reinforced the value of components of informal, learner-directed learning environments that extend beyond the restrictions of the formal online learning space. While learners did not take full advantage of the numerous external resources and informal interactions that were available, participants expressed overwhelming satisfaction with the content and formal interactions designed and therefore may have been less likely to engage in superfluous interactions. Yet, the informal learning environment that was crafted placed maximum control with the learners. Such informal learning environments provide an open venue for learners to connect with others interested in the same concepts either in a different course section or at a different stage of the course (Rhode, 2006).

Responses from participants support Paulsen's (1993) Theory of Cooperative Freedom, which argues that many students who choose a distance learning format do so in search of freedom from not only the time and place learning constraints, but also freedom to choose the type of media and content, times of access, and pace of the learning. Participants unanimously noted that the unique self-paced format was a pivotal factor enabling them to enroll in an online program of study. Such responses give credence to the call for flexible and emergent learning designs that meet the needs of an ever-changing adult learner population.

Participants in this study esteemed quality interactions with content and the instructor above interactions with other learners, which reiterates the need for instructional design that facilitates active engagement with content and instructor-learner interaction. Although some may contend that true self-paced learning models diminish the role of the instructor, a host of hybrid approaches to self-paced online education have been shown to accommodate flexibility and customizability and incorporate considerable measures of instructor-learner and learner-learner interactions. As participants' responses in this study reiterate, a balanced approach to incorporating the various interactions is often preferred by adult learners in the self-paced online course.

Research Question 3: What forms of interaction do adult learners identify as equivalent in selfpaced online courses?

Participants identified interaction with the instructor and content as very nearly equivalent in a self-paced online course. Participants pointed out that quality interaction with content is indispensable in the self-paced learning environment and can not in any way be replaced. They also indicated that interaction with the instructor could potentially be diminished and compensated for through increased quality interactions with content or learners. Participants further noted that while interaction with other learners is desirable within the self-paced learning environment, the self-paced nature of the course makes such interactions challenging. Therefore, learners were willing to forgo interpersonal interactions deemed by some as tangential in exchange for the flexibility afforded by the self-paced learning approach. 
In a granular analysis of the various interaction activities, participants generally reported the activity of blogging as equivalent or superior to asynchronous discussion via the discussion board in Blackboard. Such findings add to the burgeoning body of research supporting the pedagogical possibilities of blogging as a flexible asynchronous communication alternative to threaded discussion via a restricted learning management system (Chen \& Bonk, 2008; Ellison \& Wu, 2008; Namwar \& Rastgoo, 2008; Schmidt, 2007). Participants also found the mix of formal and informal interactions with the content and instructor as essential to the optimal self-paced online learning experience. Interactions with other learners, both in the formal learning space as well as fostered by informal activities, were seen as tangential and while helpful are not necessary to achieve a desirable learning outcome.

Research Question 4: What impact do adult learners perceive interaction to have on their selfpaced online learning experience?

Participants reported their experiences of the various types of interactions they engaged in throughout a self-paced online course and indicated the important part that the interactions with the instructor and course content played in their overall online learning experience. While interaction with other learners was not the most influential component of the particular course studied, the logical assumption may be drawn that in other courses where interpersonal discussion with other learners is in fact maximized, such interactions could be equally important.

Participants confirmed that quality interaction is a critical component of a quality self-paced online learning experience. Such conclusions support long-standing claims about the necessity for systematic design of instruction that encourage pedagogically-sound methods and incorporate emerging approaches as appropriate to meet the needs of learners (Kays \& Sims, 2006; Koszalka $\&$ Ganesan, 2004). The substance and frequency of expressed quality interactions deemed necessary by learners may in fact vary from one learner population to another and may be influenced by the specific context and discipline. Participants refuted the claim that interaction with the instructor or content could be diminished or eliminated and compensated for by other forms of interaction. Further studies will be necessary to explore whether such hypotheses are in fact confirmed.

As Nicol, Minty, and Sinclair (2003) note, "The social context of online learning is qualitatively different from face-to-face learning and...this has significant implications for online learning design" (p. 270). Interaction is a key component to the development of the distinctive social context of online learning. Interaction may serve numerous purposes within the online learning environment, but the primary focus for many instructional designers and instructors may continue to center around improving student outcomes within the online learning experience.

\section{Recommendations}

While this study provides important contributions to the field, some recommendations may enhance its impact as well as guide further studies. As with any exploratory study, the insights gleaned provide an initial and focused understanding of an educational intervention from the 
perspective of those involved and pave the way for future studies. The very nature of such inquiry is based on the premise that multiple perspectives for any given experience exist and that the significance of the experience to the participants is what comprises reality (McMillan, 2000). The rich insights gleaned from the participants are specific to that population and cannot be projected upon other classifications of individuals. This study focused on learner preferences for interaction in a self-paced online learning environment and did not simultaneously investigate instructorpreferred or administration-preferred tenets worthy of analysis. Further studies could explore such perspectives within the self-paced online learning environment as well as extend beyond a single institution in order to see if the sentiments expressed by learners in the selected course sections are isolated to the specific course or program or are more indicative of interaction trends in other contexts.

Similar future studies would add valuable contributions to the field by studying interaction in similar course environments, but also in alternative institutions where the researcher is not the instructor and with multiple sections of a particular course facilitated by different instructors who have different approaches to interacting with students. Successive studies could also involve a variety of learner populations (e.g., of different ages and socio-cultural status) to determine whether such influences impact interaction. Furthermore, additional studies are necessary to measure the affect that emerging interaction types have on the overall learning experience. While this study focused on the perceptions and values of learners regarding interaction equivalency, further study of learners' behavior is needed to determine whether online learners actually accept or reject interaction equivalency. In particular, it would be helpful for instructors and designers alike to understand in what instances learners will forgo interaction with one another to maintain the flexibility of the distance learning experience.

This study briefly explored learners' preferences for asynchronous discussion and compared a discussion board with the more open format of a blog. Further research is necessary to explore the unique aspects of emergent asynchronous communications approaches such as blogging, collaborative authorship, social bookmarking, and social networking compared to more traditional asynchronous online communication approaches. In particular, when given the choice, do learners prefer a more open form of communication made possible through emergent computer-mediated communication technologies to the discussion board provided in an LMS? In addition, to what extent can a social network system meet the needs of designers, instructors, and learners and therefore be capable of replacing an LMS? Finally, it would be beneficial to learn in future studies what impact course size may have on the self-paced online learning experience.

\section{Conclusions}

A host of interactions are possible in contemporary online learning environments. Some are viewed as essential while others may be viewed as supplemental. Prior to conducting this study, it was proposed that one or more types of interaction could potentially surface as being preferable for adult learners in the self-paced online learning environment. Others have conjectured that learners may value formal, learner-instructor interaction highest, but little evidence was previously available in the literature to support or refute the notion of interaction equivalency 
among interaction modalities. This study demonstrated that depending on the specific circumstance, not all forms of interaction may be either equally valued by learners or effective. Participants reported that informal interactions were as important as formal interactions in determining the quality of the online learning experience.

Participants also maintained that the flexibility and independence characteristics of self-paced Page $\mid 16$ learning opportunities supplanted the need for certain types of interaction. They were willing to forgo interaction with one another to preserve the flexibility of their self-paced studies. In addition, the activity of blogging was shown to be equivalent to or even superior to instructordirected asynchronous discussion via the discussion board in a LMS. While it may be possible to design opportunities for interpersonal interaction that rival interaction with the instructor or content, in the particular self-paced online learning environment that was studied, this was not the case. And as learners' preferences indicated that one or more types of interaction were valued over the other, it is certainly possible that in other learning environments such findings may differ. Further study is necessary to determine whether the initial insights of participants in this limited study reflect noteworthy trends in interaction or are merely an isolated instance. 


\section{References}

Abdulla, A. G. (2006). Distance learning students' perceptions of the online instructor roles and competencies. Dissertation Abstracts International, 65(07), 2409. (UMI No. 3137394)

Anderson, T. (2003). Getting the mix right again: An updated and theoretical rationale for interaction. The International Review of Research in Open and Distance Learning, 4 (2). Retrieved July 8, 2006, from http://www.irrodl.org/index.php/irrodl/article/view/149/230

Anderson, T., Annand, D., \& Wark, N. (2005). The search for learning community in learner paced distance education: Or, 'Having your cake and eating it, too!'. Australasian Journal of Educational Technology, 21 (2), 222-241. Retrieved July 7, 2006, from http://www.ascilite.org.au/ajet/ajet21/anderson.html

Anderson, T., \& Dron, J. (2007). Groups, networks and collectives in social software for elearning, 2007 European Conference on E-Learning. Copenhagen, Denmark.

Beldarrain, Y. (2006). Distance education trends: Integrating new technologies to foster student interaction and collaboration. Distance Education, 27(2), 139-153.

Berge, Z. L. (1999). Interaction in post-secondary web-based learning. Educational Technology, 39(1), 5-11.

Bibeau, S. (2001). Social presence, isolation, and connectedness in online teaching and learning: From the literature to real life. Journal of Instructional Delivery Systems, 15(3), 35-39.

Brown, M., \& Long, P. D. (2006). Trends in learning space design. In D. G. Oblinger (Ed.), Learning spaces: Educause.

Brown, R. E. (2001). The process of community-building in distance learning classes. Journal of Asynchronous Learning Networks, 5(2), 18-35.

Brown, S. W., \& King, F. B. (2000). Constructivist pedagogy and how we learn: Educational psychology meets international studies. International Studies Perspectives, 1(3), 245-255.

Chen, W., \& Bonk, C. (2008). The use of weblogs in learning and assessment in Chinese higher education: Possibilities and potential problems. International Journal on E-Learning, $7(1), 41-65$.

Clark, R. E. (1994). Media will never influence learning. Educational Technology Research and Development, 42(2), 21-29.

Dalsgaard, C. (2006). Social software: E-learning beyond learning management systems. European Journal of Open, Distance and E-Learning, 2006 (2). Retrieved September 26, 
Interaction Equivalency in Self-Paced Online Learning Environments: An Exploration of Learner Preferences Rhode

2006, from http://www.eurodl.org/materials/contrib/2006/Christian_Dalsgaard.htm

Dobrovolny, J. (2006). How adults learn from self-paced, technology-based corporate training:

New focus for learners, new focus for designers. Distance Education, 27(2), 155-170.

Dron, J. (2006). Social software and the emergence of control, The 6th IEEE International

Conference on Advanced Learning Technologies. Kerkrade, The Netherlands.

Dron, J. (2007). Designing the undesignable: Social software and control. Educational

Technology \& Society, 10(3), 60-71.

Ellis, R. A., Jarkey, N., Mahony, M. J., Peat, M., \& Sheely, S. (2007). Managing quality improvement of eLearning in a large, campus-based university. Quality Assurance in Education, 15(1), 9-23.

Ellison, N., \& Wu, Y. (2008). Blogging in the classroom: A preliminary exploration of student attitudes and impact on comprehension. Journal of Educational Multimedia and Hypermedia, 17(1), 99-122.

Fink, A., \& Kosecoff, J. (1998). How to conduct surveys: A step-by-step guide (2nd ed.). Thousand Oaks, CA: Sage Publications.

Flottemesch, K. (2000). Building effective interaction in distance education: A review of the literature. Educational Technology, 40(3), 46-51.

Gallien, T., \& Early, J. O. (2008). Personalized versus collective instructor feedback in the online courseroom: Does type of feedback affect student satisfaction, academic performance and perceived connectedness with the instructor? International Journal on E-Learning, 7(3), 463-476.

Garrison, D. R. (2003). Cognitive presence for effective asynchronous online learning: The role of reflective inquiry, self-direction and metacognition. In J. Bourne \& J. C. Moore (Eds.), Elements of quality online education: Practice and direction. Needham, MA: The Sloan Consortium.

Garrison, D. R., \& Anderson, T. (2003). E-learning in the 21 st century: A framework for research and practice. London: Routledge Falmer.

Garrison, D. R., \& Cleveland-Innes, M. (2005). Facilitating cognitive presence in online learning: Interaction is not enough. American Journal of Distance Education, 19(3), 133-148.

Greene, H. C. (2005). Creating connections: A pilot study of an online community of learners. Journal of Online Interactive Learning, 3 (3). Retrieved September 2, 2006, from 
Interaction Equivalency in Self-Paced Online Learning Environments: An Exploration of Learner Preferences Rhode

http://www.ncolr.org/jiol/issues/PDF/3.3.3.pdf

Heinemann, M. H. (2003). Teacher-student interaction online and learning in web-based graduate theological education. Dissertation Abstracts International, 64(04), 1189. (UMI No. 3087174)

Hirumi, A. (2006). Analysing and designing e-learning interactions. In C. Juwah (Ed.), Interactions in online education: Implications for theory and practice (pp. 46-71). New York: Routledge.

Ho, C.-H. (2005). Evaluating online interaction in an asynchronous learning environment: A conversation analysis approach. Dissertation Abstracts International, 66(02), 473. (UMI No. 3164602)

Hodge, E., Bossé, M. J., Foulconer, J., \& Fewell, M. (2006). Mimicking proximity: The role of distance education in forming communities of learning. International Journal of Instructional Technology \& Distance Learning, 3 (12). Retrieved January 14, 2007, from http://www.itdl.org/Journal/Dec_06/article01.htm

Howland, J. L., \& Moore, J. L. (2002). Student perceptions as distance learners in internet-based courses. Distance Education, 23(2), 183-195.

Jonassen, D. H. (1999). Designing constructivist learning environments. In C. M. Reigeluth (Ed.), Instructional-design theories and models: A new paradigm of instructional theory (Vol. II, pp. 115-140). Mahwah, NJ: Lawrence Erlbaum Associates.

Jung, I., Choi, S., Lim, C., \& Leem, J. (2002). Effects of different types of interaction on learning achievement, satisfaction and participation in web-based instruction. Innovations in Education and Teaching International, 39(2), 153-162.

Juwah, C. (2006). Introduction. In C. Juwah (Ed.), Interactions in online education: Implications for theory and practice (pp. 1-5). New York: Routledge.

Kahn, B. H. (2007). Flexible learning in an information society. Hershey, PA: Information Science Publishing.

Kays, E., \& Sims, R. (2006). Reinventing and reinvigorating instructional design: A theory for emergent learning. In L. Markauskaite, P. Goodyear \& P. Reimann (Eds.), Proceedings of the 23rd annual conference of the Australasian society for computers in learning in tertiary education: Who's Learning? Whose Technology? (pp. 409-412). Sydney: Sydney University Press.

Kearsley, G. (1995). The nature and value of interaction in distance education. In M. Beaudoin (Ed.), Distance education symposium 3: Instruction (pp. 83-92). University Park, PA: 
Interaction Equivalency in Self-Paced Online Learning Environments: An Exploration of Learner Preferences Rhode

American Center for the Study of Distance Education.

Klein, J. D., Spector, J. M., Grabowski, B. L., \& Teja, I. (2004). Instructor competencies: Standards for face-to-face, online, and blended settings. Greenwich, CT: Information Age Publishing.

Koszalka, T. A., \& Ganesan, R. (2004). Designing online courses: A taxonomy to guide strategic use of features available in course management systems (CMS) in distance education. Distance Education, 25(2), 243-256.

Kozma, R. B. (1994). A reply: Media and methods. Educational Technology Research and Development, 42(3), 11-14.

Lee, J., Carter-Wells, J., Glaeser, B., Ivers, K., \& Street, C. (2006). Facilitating the development of a learning community in an online graduate program. The Quarterly Review of Distance Education, 7(1), 13-33.

Lee, M. J. W., \& McLoughlin, C. (2007). Teaching and learning in the Web 2.0 era: Empowering students through learner-generated content. International Journal of Instructional Technology and Distance Learning, 4(10), 21-34.

Mann, S. J. (2005). Alienation in the learning environment: A failure of community? Studies in Higher Education, 30(1), 43-55.

Maor, D. (2003). The teacher's role in developing interaction and reflection in an online learning community. Educational Media International, 40(1/2), 127-138.

Mayes, T. (2006). Theoretical perspectives on interactivity in e-learning. In C. Juwah (Ed.), Interactions in online education: Implications for theory and practice (pp. 9-26). New York: Routledge.

McLoughlin, C., \& Lee, M. J. W. (2008a). Future learning landscapes: Transforming pedagogy through social software. Innovate Journal of Online Education, 4(5).

McLoughlin, C., \& Lee, M. J. W. (2008b). The 3 P's of pedagogy for the networked society: Personalization, participation, and productivity. International Journal of Teaching and Learning in Higher Education, 20(1), 10-27.

McMillan, J. H., \& Schumacher, S. (2006). Research in education: Evidence-based inquiry (6th ed.). Boston: Pearson.

Mezirow, J. (1997). Cognitive processes: Contemporary paradigms of learning. In P. Sutherland (Ed.), Adult learning: A reader. Sterling, VA: Kogan Page. 
Interaction Equivalency in Self-Paced Online Learning Environments: An Exploration of Learner Preferences Rhode

Moore, M. G. (1993). Three types of interaction. In K. Harry, M. John \& D. Keegan (Eds.), Distance education: New perspectives (pp. 19-24). New York: Routledge.

Namwar, Y., \& Rastgoo, A. (2008). Weblog as a learning tool in higher education. Turkish Online Journal of Distance Education, 9 (3). Retrieved December 29, 2008, from http://tojde.anadolu.edu.tr/tojde31/articles/article_15.htm

Ngwenya, J., Annand, D., \& Wang, E. (2004). Supporting asynchronous discussions among online learners. In T. Anderson \& F. Elloumi (Eds.), Theory and practice of online learning (pp. 319-348). Athabasca AB Canada: Athabasca University.

Nicol, D. J., Minty, I., \& Sinclair, C. (2003). The social dimensions of online learning. Innovations in Education and Teaching International, 40(3), 270-281.

Ouzts, K. (2006). Sense of community in online courses. The Quarterly Review of Distance Education, 7(3), 285-296.

Pawan, F., Paulus, T. M., Yalcin, S., \& Chang, C. (2003). Online learning: Patterns of engagement and interactions among in-service teachers. Language Learning \& Technology, 7(3), 119-140.

Perry, B., \& Edwards, M. (2005). Exemplary online educators: Creating a community of inquiry. Turkish Online Journal of Distance Education, 6(2).

Picciano, A. G. (2002). Beyond student perceptions: Issues of interaction, presence, and performance in an online course. Journal of Asynchronous Learning Networks, 6(1), 2140.

Ravenscroft, A., \& McAlister, S. (2006). Designing interaction as a dialogue game: Linking social and conceptual dimensions of the learning process. In C. Juwah (Ed.), Interactions in online education: Implications for theory and practice (pp. 75-90). New York: Routledge.

Rhode, J. F. (2006). Anatomy of a socially-constructed self-paced learning environment. Retrieved August 20, 2007, from http://www.idolresources.com/?p=416

Rovai, A. P. (2002). Building a sense of community at a distance. International Review of Research in Open and Distance Learning, 3(1).

Rovai, A. P., \& Barnum, K. T. (2003). On-line course effectiveness: An analysis of student interactions and perceptions of learning. Journal of Distance Education, 18 (1). Retrieved March 17, 2007, from http://cade.athabascau.ca/vol18.1/rovai.pdf 
Interaction Equivalency in Self-Paced Online Learning Environments: An Exploration of Learner Preferences Rhode

Russell, T. L. (2005). No significant difference phenomenon. Retrieved December 5, 2005, from http://www.nosignificantdifference.org/

Russo, T. C., \& Benson, S. (2005). Learning with invisible others: Perceptions of online presence and their relationship to cognitive and affective learning. Educational Technology \& Society, 8(1), 54-62.

Schmidt, J. (2007). Blogging practices: An analytical framework. Journal of Computer-Mediated Communication, 112(4), 1409-1427.

Sherry, L. (1996). Issues in distance learning. International Journal of Educational Telecomunications, 1 (4), 337-365. Retrieved July 3, 2007, from http://carbon.cudenver.edu/ 1sherry/pubs/issues.html

Smith, G. G., Torres-Ayala, A. T., \& Heindel, A. J. (2008). Disciplinary differences in e-learning instructional design: The case of mathematics. Journal of Distance Education, 22 (3), $63-$ 88. Retrieved December 29, 2008, from http://www.jofde.ca/index.php/jde/article/view/91/704

Stein, D. S., Wanstreet, C. E., Calvin, J., Overtoom, C., \& Wheaton, J. E. (2005). Bridging the transactional distance gap in online learning environments. The American Journal of Distance Education, 19(2), 105-118.

Strachota, E. M. (2003). Student satisfaction in online courses: An analysis of the impact of learner-content, learner-instructor, learner-learner and learner-teacher interaction. Dissertation Abstracts International, 64(08), 2746. (UMI No. 3100902)

Su, B. (2006). Experiences of and preferences for interactive instructional activities in online learning environment. Dissertation Abstracts International, 67(04), (UMI No. 3215221)

Su, B., Bonk, C. J., Magjuka, R. J., Liu, X., \& Lee, S.-h. (2005). The importance of interaction in web-based education: A program-level case study of online MBA courses. Journal of Interactive Learning Research, 4(1), 1-19.

Swan, K. (2002). Building learning communities in online courses: The importance of interaction. Education, Communication \& Leadership, 2(1), 23-49.

Swan, K., \& Shih, L.-F. (2005). On the nature and development of social presence in online course discussions. Journal of Asynchronous Learning Networks, 9(3), 115-136.

Taylor, J. C. (2001, April). Fifth generation distance education. Keynote presentation at the 20th ICDE World Conference, Düsseldorf, Germany. 
Interaction Equivalency in Self-Paced Online Learning Environments: An Exploration of Learner Preferences Rhode

Tu, C.-H., \& McIsaac, M. S. (2002). The relationship of social presence and interaction in online classes. The American Journal of Distance Education, 16(3), 131-150.

Twigg, C. A. (2003). Improving Learning and reducing costs: New models for online learning. Educause Review, 38(5), 28-38.

Varvel, V. E. (2007). Master online teacher competencies. Online Journal of Distance Learning Administration, 10 (1). Retrieved June 21, 2007, from http://www.westga.edu/ distance/ojdla/spring101/varvel101.htm

Wanstreet, C. E. (2006). Interaction in online learning environments. Quarterly Review of Distance Education, 7(4), 399-411.

Wiley, D. (2006). Scalability and sociability in online learning environments. In H. F. O'Neil \& R. S. Perez (Eds.), Web-based learning: Theory, research, and practice (pp. 295-306). Mahwah, NJ: Lawrence Erlbaum Associates.

Willging, P. A., \& Johnson, S. D. (2004). Factors that influence students' decision to drop out of online courses. Journal of Asynchronous Learning Networks, 8(4), 105-118.

Yang, Y., \& Cornelious, L. F. (2005). Preparing instructors for quality online instruction. Online Journal of Distance Learning Administration, 8 (1). Retrieved October 13, 2005, from http://www.westga.edu/\%7Edistance/ojdla/spring81/yang81.htm

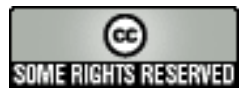

